\title{
Temporal Trends in Acute Myocardial Infarction Incidence and Mortality Between 2006 and 2016 in Tokyo - Report From the Tokyo CCU Network -
}

\author{
Takeshi Yamamoto, MD, PhD; Nobuko Yoshida; \\ Morimasa Takayama, MD, PhD; Tokyo CCU Network
}

\begin{abstract}
Background: Temporal trends in the incidence and mortality of acute myocardial infarction (AMI) have not been fully clarified in Japan.
Methods and Results: The Tokyo CCU network collects information every 3 months regarding the number of AMI cases, age of patients and in-hospital mortality. Age-adjusted hospitalized AMI numbers were unchanged from 2006 to 2016 (40.7/100,000 persons/year in 2016). Annual age-adjusted in-hospital mortality decreased slightly (5.8\% in 2006 to $5.2 \%$ in 2016$)$.
\end{abstract}

Conclusions: A steady trend of AMI incidence was observed over the past 11 years in the Tokyo metropolitan area. In-hospital mortality decreased slightly but significantly, with the establishment of primary percutaneous coronary intervention.

Key Words: Acute myocardial infarction; Aging; Epidemiology

A cute myocardial infarction (AMI) is a major cause of death and an important public health problem worldwide. Decreasing trends in the incidence and mortality of AMI have been reported in Western countries over the past decade, ${ }^{1}$ but the temporal trends for AMI have not been fully clarified in Japan, especially after the establishment of primary percutaneous coronary intervention (PCI) and with the progressive aging of society. There have been a few registry studies of AMI but most of them included relatively small numbers of patients..$^{2-4}$ As of October 1, 2015, the population of the Tokyo metropolitan area was estimated to be 13.5 million and expressed as approximately $10 \%$ of Japan's total population. Here, the Tokyo CCU Network operates to treat patients with emergency cardiovascular diseases as promptly as possible, with the help of ambulance units through the control room of the Tokyo Fire Department. ${ }^{5,6}$ We set out to assess recent temporal trends in hospitalization and in-hospital mortality rates for AMI in the Tokyo CCU Network.

\section{Methods}

The Tokyo CCU network continually collects data regarding the numbers of AMI cases, age, sex, and in-hospital mortality, grouping these into three-month periods. The collected data have included Killip classification on admission since 2009. Diagnoses of AMI are based on the universal definition. ${ }^{7}$ WHO-MONICA diagnostic criteria ${ }^{8}$ were permitted when troponin levels were difficult to assess. The therapeutic strategies for AMI were decided by the cardiologists in each hospital, and all patients were treated according to the Japanese Circulation Society, ESC and ACCF/AHA guidelines for the diagnosis and treatment of AMI. Patients with cardiac arrest on hospital arrival were excluded. The requirement for informed consent was waived because all data were anonymized. This study was approved by the institutional review board of the Tokyo CCU Network Scientific Committee.

\section{The Tokyo CCU Network}

The Tokyo CCU network was established in 1978 with the goal of treating patients with emergency cardiovascular events as promptly as possible, with the help of ambulance units dispatched through the Tokyo Fire Department. ${ }^{5}$ All 72 hospitals (as of December 31, 2016) participating in the Tokyo CCU network aim to perform emergency PCI within $1 \mathrm{~h}$ of the patient's arrival at the hospital. Deducing from the regional distribution of these 72 hospitals, the Tokyo CCU network probably includes $95 \%$ of all patients who have had an AMI within the greater Tokyo metropolitan area, serving a population of 13.5 million. ${ }^{6}$

\section{Statistical Analysis}

Over the 11 years from 2006 to 2016, there were 51,639 hospitalizations (39,113 male; 12,526 female) for AMI in Tokyo CCU Network hospitals. Age-adjusted hospitalized

Received February 28, 2019; revised manuscript received March 25, 2019; accepted March 29, 2019; J-STAGE Advance Publication released online April 20, 2019 Time for primary review: 25 days

Tokyo Metropolitan Cardiovascular Care Unit Council, Tokyo, Japan

Tokyo CCU Network is listed in Supplementary Appendix.

Mailing address: Takeshi Yamamoto, MD, PhD, Senior Assistant Professor, Division of Cardiovascular Intensive Care, Nippon Medical School Hospital. Secretary General, Tokyo Metropolitan Cardiovascular Care Unit Council, 2-5-4 Yoyogi, Shibuya-ku, Tokyo 151-0053, Japan. E-mail: yamamoto56@nms.ac.jp

ISSN-1346-9843 All rights are reserved to the Japanese Circulation Society. For permissions, please e-mail: cj@j-circ.or.jp 


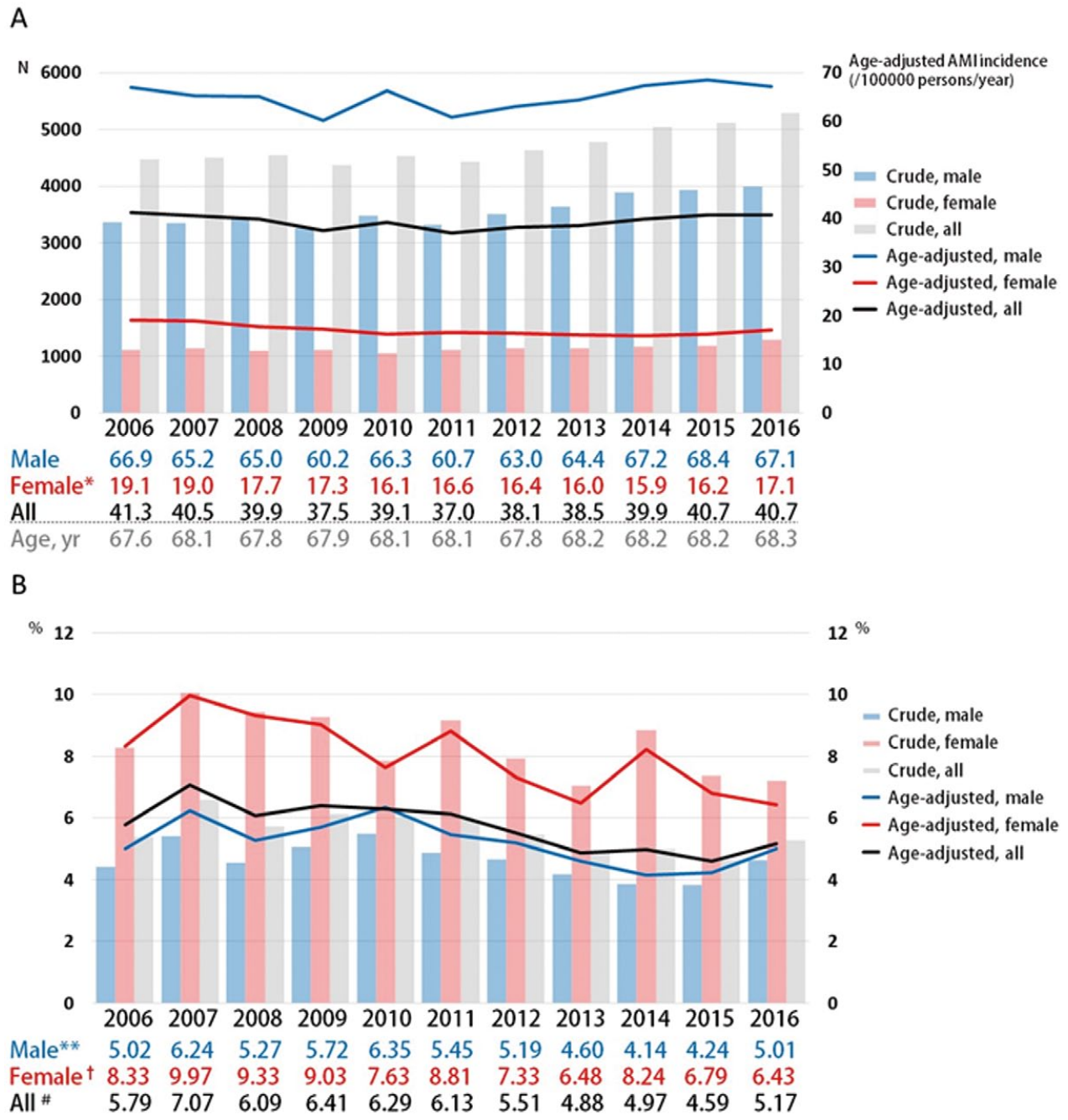

Figure 1. Temporal trends in age-adjusted incidence (/100,000 persons/year) (A) and in-hospital mortality (B) of $A M I .{ }^{*} P$ value for trend=0.01, ${ }^{\star \star} \mathrm{P}$ value for trend $=0.052,{ }^{\dagger} \mathrm{P}$ value for trend $=0.004,{ }^{*} \mathrm{P}$ value for trend=0.016. AMl, acute myocardial infarction.

AMI per 100,000 person-years was calculated. To adjust for age distribution differences among the time period, we used a direct method with the 2010 Japanese population census as the standard population. ${ }^{9}$ We also used the Tokyo metropolitan population per year reported by the Tokyo Metropolitan municipality. The significance of trends in age-adjusted incidence and in-hospital mortality were assessed using the Cochran-Armitage trend test. These analyses were performed using XLSTAT software version 2017 (Addinsoft, New York, NY, USA). $\mathrm{P}<0.05$ was considered statistically significant.

\section{Results}

\section{Temporal Trends in the Incidence of AMI}

Numbers of crude hospitalized AMI patients gradually increased annually; however, age-adjusted hospitalized AMI numbers (/100,000 persons/year) were unchanged from 2006 to 2016. Age-adjusted hospitalized AMI numbers decreased slightly for women $(\mathrm{P}=0.01)$ (Figure 1A). Average age was unchanged annually, with an overall age of 68.3 years for men and women together; 65.9 years for men and 75.7 years for women in 2016 . When analyzed by age, the age-specific hospitalized AMI numbers gradually increased in younger patients aged $\leq 59$ years $(\mathrm{P}=0.036)$ and tended to decrease in older patients aged $\geq 80$ years $(\mathrm{P}=0.052)$ (Figure 2A). Furthermore, when separated by sex, the age-specific hospitalized AMI numbers gradually increased in male patients aged $60-69$ years $(\mathrm{P}=0.024)$ and decreased in female patients aged $\geq 80$ years $(\mathrm{P}=0.036)$.

\section{Temporal Trends in In-Hospital Mortality}

The crude in-hospital mortality slightly decreased annually in the overall $(\mathrm{P}=0.008)$, male $(\mathrm{P}=0.042)$, and female $(\mathrm{P}=0.003)$ patient groups. The same trend was noted in the age-adjusted analysis for the overall $(\mathrm{P}=0.016)$ and female $(\mathrm{P}=0.004)$ patient groups, whereas it tended to decrease in male patients $(\mathrm{P}=0.052)$ (Figure 1B). When analyzed by age, the age-specific mortality decreased in older patients aged $\geq 80$ years $(\mathrm{P}=0.016)$ and $70-79$ years $(\mathrm{P}=0.024)$ (Figure 2B). Furthermore, when separated by sex, the age-specific mortality decreased in female patients aged 


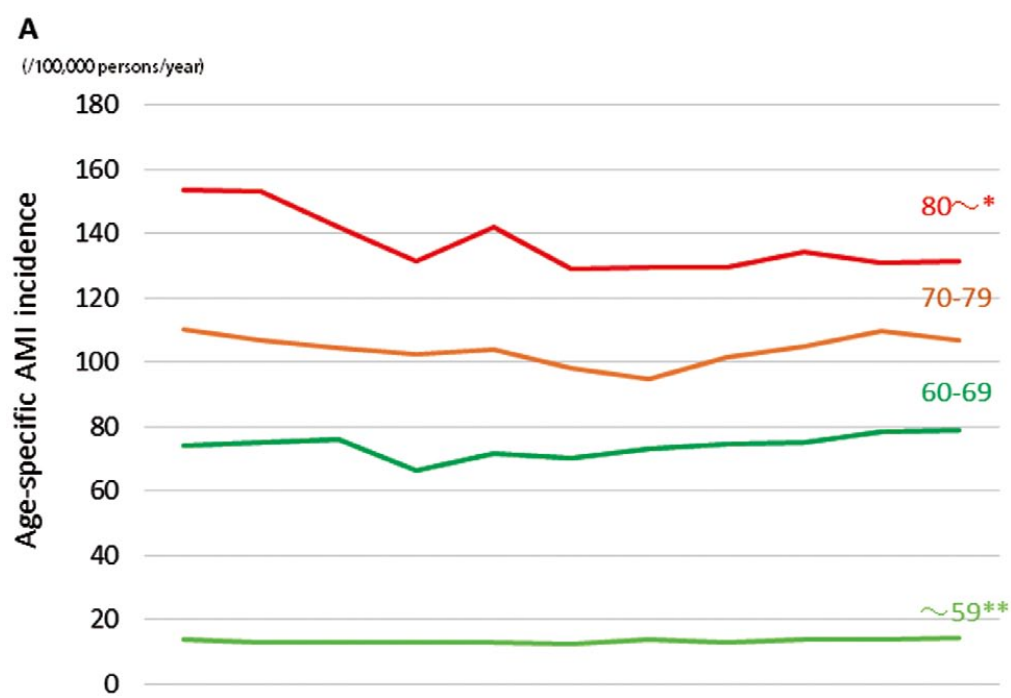

20062007200820092010201120122013201420152016

B

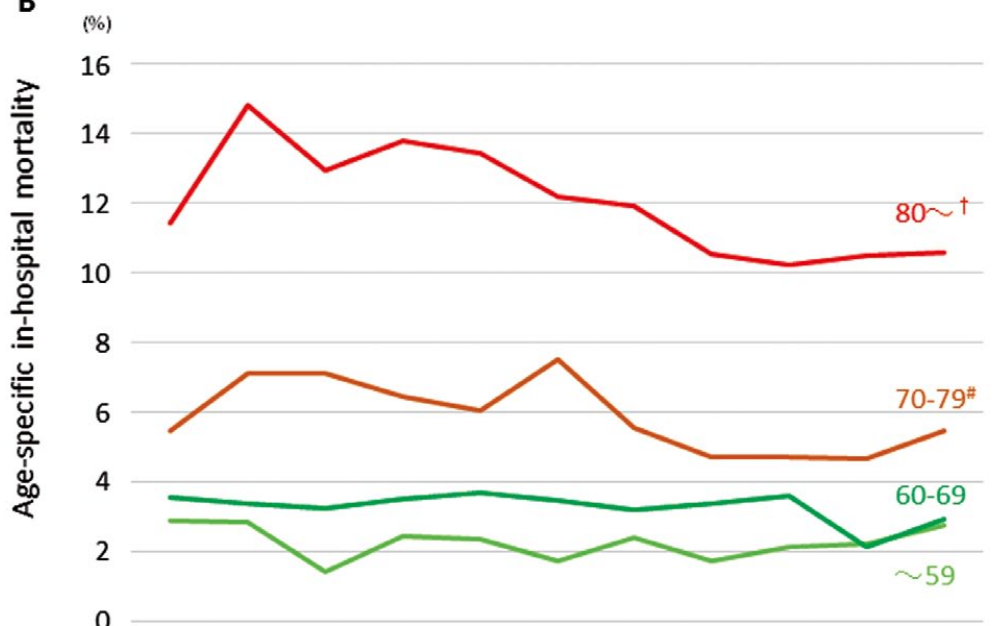

20062007200820092010201120122013201420152016

Figure 2. Temporal trends in age-specific incidence (/100,000 persons/year) (A) and in-hospital mortality $(\mathbf{B})$ of AMI. *P value for trend $=0.052,{ }^{* *} P$ value for trend $=0.036$, ${ }^{\dagger} P$ value for trend $=0.016$, "P value for trend= 0.024. AMI, acute myocardial infarction.

$\geq 80$ years $(\mathrm{P}=0.006)$ and $60-69$ years $(\mathrm{P}=0.036)$.

\section{Temporal Trends in the Incidence and In-Hospital Mortality According to Killip Classification}

In analysis by Killip class, the numbers of age-adjusted hospitalized AMI patients slightly increased annually in Killip I $(\mathrm{P}=0.026)$ and tended to increase in Killip IV $(\mathrm{P}=0.061)$ (Figure 3A). The age-adjusted in-hospital mortality decreased significantly in patients with Killip IV classification $(\mathrm{P}=0.004)$, and was unchanged in the remaining classes (Figure 3B).

\section{Discussion}

The overall numbers of age-adjusted hospitalized AMI patients in Tokyo were unchanged from 2006 to 2016. The same trend was noted for male patients, but a decreasing trend among female patients was observed. The Table shows the temporal trends in the age-adjusted incidence of AMI in Japan. It has been recently reported that the incidence of AMI is steadily decreasing in Kumamoto
Prefecture $^{2}$ and the Northern Iwate rural area ${ }^{4}$ for both sexes. In the same period of the Miyagi AMI Registry Study, ${ }^{3}$ a decreasing trend among only female patients was observed, as in the present study. Regional prefectural differences appear to be explained by differences in the age of the study population. According to an annual survey of the Japanese Registry of All Cardiac and Vascular Diseases (JROAD) participating training hospitals of the Japanese Circulation Society, the number of patients with AMI hospitalized per year was 73,421 in $2016 .{ }^{10}$ An estimate for the total population in Japan for that period was $57.8 / 100,000$ persons/year. In the present study, the agespecific incidence of AMI gradually increased in younger patients and decreased in older patients. These results may be related to the increased prevalence of metabolic risk factors in young populations and the increased use of antihypertensive agents and statins for primary prevention in the elderly. ${ }^{3,11}$

A universal definition of AMI using cardiac troponin was widely used during the study period. Thus there is potential for an increase in the diagnostic numbers rather 


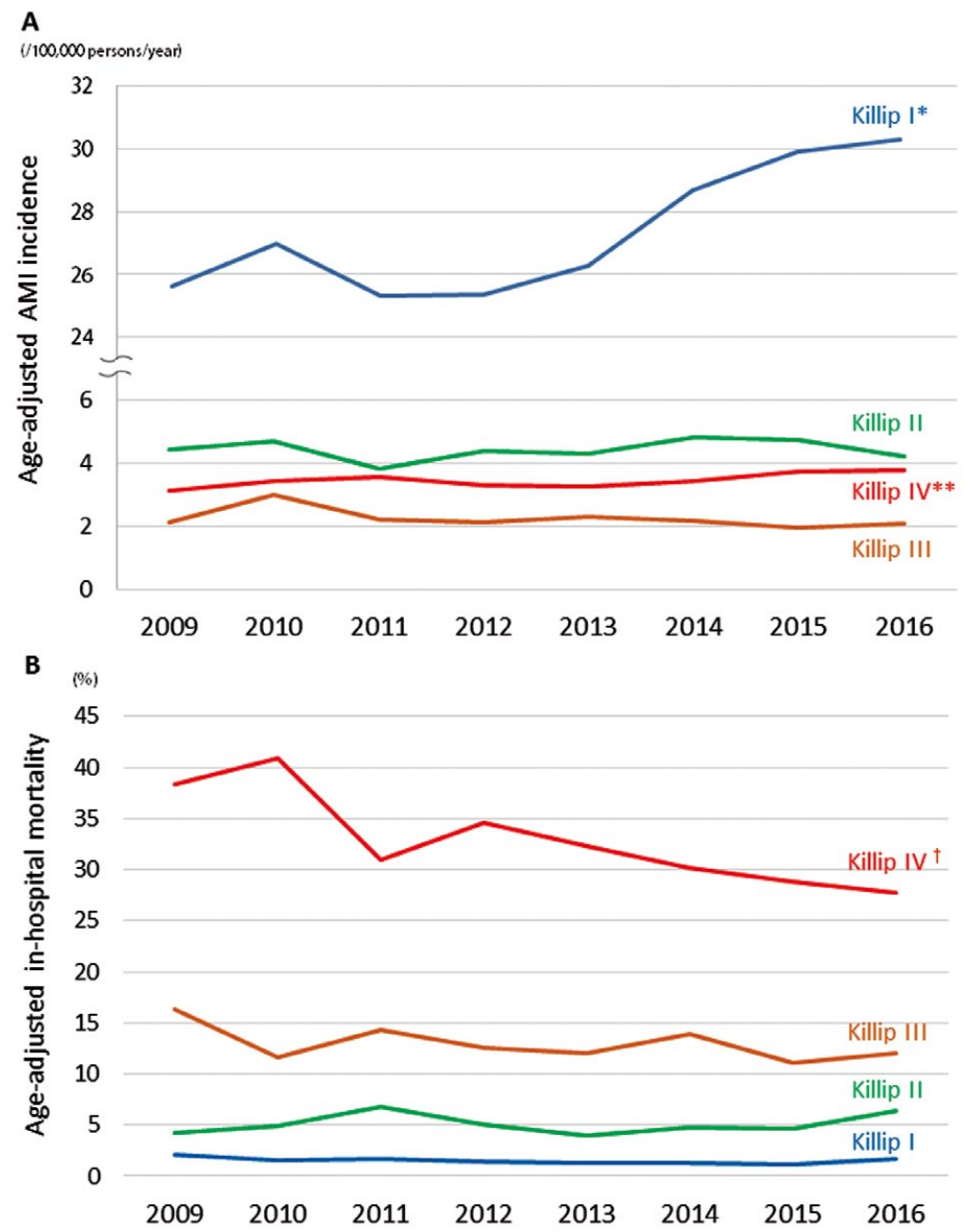

Figure 3. Temporal trends in age-adjusted incidence (/100,000 persons/year) (A) and in-hospital mortality (B) according to Killip classification. * $P$ value for trend $=0.026$, ${ }^{* *} \mathrm{P}=0.061$, ${ }^{\mathrm{P}} \mathrm{P}$ value for trend $=0.004$. AMI, acute myocardial infarction.

\begin{tabular}{|c|c|c|c|}
\hline $\begin{array}{c}\text { Area } \\
\text { (reference no.) }\end{array}$ & Period & Sex & $\begin{array}{c}\text { Incidence } \\
(/ 100,000 \text { persons/year) }\end{array}$ \\
\hline \multirow[t]{3}{*}{ Kumamoto² } & 2004-2011 & Male & $93.1 \rightarrow 70.7$ \\
\hline & & Female & $33.0 \rightarrow 20.7$ \\
\hline & & Overall & $59.2 \rightarrow 43.1$ \\
\hline \multirow[t]{2}{*}{ Miyagi $^{3}$} & 2005-2014 & Male & $61.3 \rightarrow 68.1$ \\
\hline & & Female & $17.7 \rightarrow 12.2$ \\
\hline \multirow[t]{2}{*}{ Northern Iwate ${ }^{4}$} & 2006-2014 & Male & $101.1 \rightarrow 82.1$ \\
\hline & & Female & $52.4 \rightarrow 28.9$ \\
\hline \multirow[t]{3}{*}{ Tokyo (Present study) } & 2006-2016 & Male & $66.9 \rightarrow 67.1$ \\
\hline & & Female & $19.1 \rightarrow 17.1$ \\
\hline & & Overall & $41.3 \rightarrow 40.7$ \\
\hline JROAD 9 & 2016 & Overall & $\begin{array}{l}\text { ( } 73,421 / \text { year; } 57.8, \text { estimated } \\
\text { from the total population) }\end{array}$ \\
\hline
\end{tabular}

AMI, acute myocardial infarction; JROAD, Japanese Registry Of All cardiac and vascular Diseases.

than in the incidence, such as cases of patients in Killip I class with only cardiac troponin elevation. In the Japanese multicenter registry of AMI diagnosed by the universal definition, non-ST elevation MI with Killip I class was more frequent in patients with only cardiac troponin eleva- tion than in those with creatine phosphokinase elevation $(87.1 \%$ vs. $71.0 \%) .{ }^{12}$ Numbers of age-adjusted hospitalized AMI patients with shock (Killip IV) increased slightly each year in the present study. Cases of delayed shock may have decreased because of the widespread use of primary PCI; 
however, cases of early shock after resuscitation from outof-hospital cardiac arrest may show a relative increase in association with the establishment of prehospital management. In the USA's nationwide inpatient sample databases, the incidence of ST-elevation MI with shock increased from $6.5 \%$ in 2003 to $10.1 \%$ in 2010.13

The age-adjusted in-hospital mortality in the present study still continued to decrease slightly but significantly, even in recent years, for the overall patients and for women. The trend appears to have been affected by reductions in the deaths of elderly patients and those in Killip IV class. The largest inpatient database in the USA shows that in elderly patients with acute coronary syndrome there is an upward trend in the rate of PCI in older adults $\geq 70$ years with any acute coronary syndrome. The rate increased from $9.4 \%$ in 1998 to $28.3 \%$ in 2013, while the in-hospital mortality rate showed a downward trend. ${ }^{14}$ The nationwide AMI registry in Japan showed elderly patients ( $\geq 80$ years) also received emergency PCI in $80 \%$ of cases..$^{15}$ Based on the US nationwide inpatient sample databases, ${ }^{12}$ the inhospital mortality of cardiogenic shock has decreased from 2003 to 2010 in synchrony with the increased use of emergency PCI.

\section{Study Limitations}

First, we used hospitalization numbers as a substitute for the incidence of AMI. Patients with cardiac arrest on hospital arrival were excluded. Second, there was no information regarding patients' characteristics and treatment in-hospital including reperfusion strategy, which may affect prognosis. A validation study using detailed registry data is needed. The present study included all patients hospitalized within the CCU network in the urban Tokyo metropolitan area. However, regional differences have been reported in the current state of emergency care for AMI between rural prefectures and Tokyo metropolitan area. ${ }^{16}$

\section{Conclusions}

A steady trend of overall AMI incidence was observed from 2006 to 2016 in the Tokyo metropolitan area. Inhospital mortality decreased slightly but significantly for the 11-year period, particularly after the establishment of primary PCI.

\section{Acknowledgments}

The authors express their special gratitude to all members of the Tokyo CCU Network and Dr. Toshiaki Otsuka for his statistical assistance.

\section{Conflict of Interest}

The authors declare that there is no conflict of interest.

\section{Funding}

This work was supported by the Tokyo Metropolitan Government. The funder had no role in the execution of this study or the interpretation of the results.

\section{References}

1. Benjamin EJ, Virani SS, Callaway $\mathrm{CW}$, Chamberlain $\mathrm{AM}$, Chang AR, Cheng S, et al. Heart disease and stroke statistics -
2018 update: A report from the American Heart Association. Circulation 2018; 137: e67-e492.

2. Kojima S, Matsui K, Ogawa H; Kumamoto Acute Coronary Events (KACE) Study Group. Temporal trends in hospitalization for acute myocardial infarction between 2004 and 2011 in Kumamoto, Japan. Circ J 2013; 77: 2841-2843.

3. Cui Y, Hao K, Takahashi J, Miyata S, Shindo T, Nishimiya K, et al. Age-specific trends in the incidence and in-hospital mortality of acute myocardial infarction over 30 years in Japan: Report from the Miyagi AMI Registry Study. Circ J 2017; 81: 520-528.

4. Nakamura M, Tanaka F, Segawa T, Takahashi T, Matsuura Y, Sakai T, et al. Temporal trends in the incidence and clinical features of acute myocardial infarction in a Japanese rural area from 2006 to 2014. Circ J 2017; 81: 1854-1861.

5. Takano T, Ida T, Tanaka K, Obayashi K, Kimura E. Prehospital care (CCU network) of acute myocardial infarction and treatment of cardiogenic shock by intra-aortic balloon pumping. Jpn Circ J 1981; 45: 623-635.

6. Miyachi H, Takagi A, Miyauchi K, Yamasaki M, Tanaka H, Yoshikawa M, et al. Current characteristics and management of ST elevation and non-ST elevation myocardial infarction in the Tokyo metropolitan area: From the Tokyo CCU network registered cohort. Heart Vessels 2016; 31: 1740-1751.

7. The Joint European Society of Cardiology/American College of Cardiology Committee. Myocardial infarction redefined: A consensus document of The Joint European Society of Cardiology/ American College of Cardiology Committee for the redefinition of myocardial infarction. J Am Coll Cardiol 2000; 36: 959-969.

8. Tunstall-Pedoe H, Kuulasmaa K, Amouyel P, Arveiler D, Rajakangas AM, Pajak A. Myocardial infarction and coronary deaths in the World Health Organization MONICA Project: Registration procedures, event rates, and case-fatality rates in 38 populations from 21 countries in four continents. Circulation 1994; 90: 583-612.

9. Statistics Bureau, Ministry of Internal Affairs and Communications. Government of Japan. http://www.stat.go.jp/english/index. html (accessed March 26, 2019).

10. Yasuda S, Miyamoto Y, Ogawa H. Current status of cardiovascular medicine in the aging society of Japan. Circulation 2018; 138: $965-967$.

11. Blais JE, Chan EW, Law SWY, Mok MT, Huang D, Wong ICK, et al. Trends in statin prescription prevalence, initiation, and dosing: Hong Kong, 2004-2015. Atherosclerosis 2018; 280: $174-$ 182.

12. Ishihara M, Fujino M, Ogawa H, Yasuda S, Noguchi T, Nakao $\mathrm{K}$, et al. Clinical presentation, management and outcome of Japanese patients with acute myocardial infarction in the troponin era: Japanese Registry of Acute Myocardial Infarction Diagnosed by Universal Definition (J-MINUET). Circ J 2015; 79: 1255 1262.

13. Kolte D, Khera S, Aronow WS, Mujib M, Palaniswamy C, Sule $\mathrm{S}$, et al. Trends in incidence, management, and outcomes of cardiogenic shock complicating ST-elevation myocardial infarction in the United States. J Am Heart Assoc 2014; 3: e000590.

14. Elbadawi A, Elgendy IY, Ha LD, Mahmoud K, Lenka J, Olorunfemi $\mathrm{O}$, et al. National trends and outcomes of percutaneous coronary intervention in patients $\geq 70$ years of age with acute coronary syndrome (from the National Inpatient Sample Database). Am J Cardiol 2019; 123: 25-32.

15. Kojima S, Nishihira K, Takegami M, Nakao YM, Honda S, Takahashi J, et al. Nationwide real-world database of 20,462 patients enrolled in the Japanese Acute Myocardial Infarction Registry (JAMIR): Impact of emergency coronary intervention in a super-aging population. Int J Cardiol Heart Vasc 2018; 20: $1-6$.

16. Masuda J, Kishi M, Kumagai N, Yamazaki T, Sakata K, Higuma T, et al. Rural-urban disparity in emergency care for acute myocardial infarction in Japan. Circ J 2018; 82: $1666-$ 1674.

\section{Supplementary Files}

Please find supplementary file(s);

http://dx.doi.org/10.1253/circj.CJ-19-0187 